Mеталлофиз. новейшие технол. / Metallofiz. Noveishie Tekhnol. (c) 2017 ИМФ (Институт металлофизики 2017 , т. 39, № 5, сс. 593-606 / DOI: 10.15407/mfint.39.05.0593 им. Г. В. Курдюмова НАН Украины) Оттиски доступны непосредственно от издателя

Фотокопирование разрешено только

Напечатано в Украине.

в соответствии с лицензией

PACSnumbers: 61.72.Hh,61.72.S-, 61.72.Yx,62.20.M-,62.25.-g, 62.40.+i,66.30.jp,68.35.Dv

\title{
Hydrogen Mobility and Its Interaction with Dislocations in Nickel-Based Inconel 718 Alloy
}

\author{
S. M. Teus
}

\author{
G. V. Kurdyumov Institute for Metal Physics, N.A.S. of Ukraine, \\ 36 Academician Vernadsky Blvd., \\ UA-03142, Kyiv, Ukraine
}

The hydrogen effects in the nickel-based alloy Inconel 718 are studied using the mechanical spectroscopy and mechanical tests. The enthalpies of hydrogen-atoms' migration and hydrogen-dislocations binding as well as the condensation temperature for the hydrogen clouds at the dislocations are determined. It is concluded that interaction of hydrogen atoms with dislocations is responsible for hydrogen embrittlement.

Key words: nickel-based alloy, hydrogen migration, hydrogen embrittlement, dislocations, mechanical spectroscopy.

Вплив водню на стоп на основі ніклю Inconel 718 досліджено із використанням методи механічної спектроскопії та механічних випробувань. Визначено ентальпію міграції атомів Гідрогену, ентальпію зв’язку Гідрогену з дислокаціями, а також температуру конденсації Гідрогенових атмосфер навколо дислокацій. Зроблено висновок про те, що взаємодія атомів Гідрогену з дислокаціями відповідає за водневу крихкість.

Ключові слова: стоп на основі ніклю, міграція Гідрогену, воднева крихкість, дислокації, механічна спектроскопія.

Влияние водорода на сплав на основе никеля Inconel 718 изучено при помощи метода механической спектроскопии и механических испытаний. Определены энтальпия миграции атомов водорода, энтальпия связи водорода с дислокациями, а также температура конденсации водородных атмосфер около дислокаций. Сделан вывод о том, что взаимодействие ато-

Corresponding author: Sergiy Myronovych Teus

E-mail: gavr@imp.kiev.ua

Please cite this article as: S. M. Teus, Hydrogen Mobility and Its Interaction with Dislocations in Nickel-Based Inconel 718 Alloy, Metallofiz. Noveishie Tekhnol., 39, No. 5: 593-606 (2017), DOI: 10.15407/mfint.39.05.0593. 
мов водорода с дислокациями ответственно за водородную хрупкость.

Ключевые слова: сплав на основе никеля, миграция водорода, водородная хрупкость, дислокации, механическая спектроскопия.

(Received April 25, 2017)

\section{INTRODUCTION}

Nickel-based superalloys represent an important class of engineering materials owing to their high corrosion resistance and excellent mechanical properties. Varying the content of alloying elements and using special thermo-mechanical procedures makes it possible to control the precipitation kinetics and morphology of phases and obtain properties needed for the certain practical applications [1, 2]. The nickelbased superalloy Inconel 718 is widely used in the applications like gas turbines, pumps, motors, nuclear reactors, etc. where the combination of corrosion resistance and appropriate mechanical stresses at elevated temperatures is required.

The strengthening of this alloy is usually achieved due to precipitation of intermetallic phases $\gamma^{\prime}$ and $\gamma^{\prime \prime}$. These phases are nanoscale and coherently bounded to the matrix, although within the certain temperature limit of their thermodynamic stability [3-7]. At the same time, despite a good corrosion resistance, the Inconel 718 alloy suffers from the hydrogen embrittlement [8-12], which results in the accelerated cracking and spontaneous degradation of mechanical properties.

Along with the grain boundaries, the precipitation/matrix interfaces are also considered as the place of accumulation of hydrogen atoms. Even taking into account that the precipitates of $\gamma^{\prime}$ and $\gamma^{\prime \prime}$ are coherently bounded with the matrix, the level of surface energy can be sufficient to form the atmospheres of hydrogen atoms at the interfaces. As shown in [11] by comparing the degree of hydrogen embrittlement in several nickel-based alloys, the precipitation-hardened alloys are more prone to hydrogen embrittlement in comparison with a single-phase alloy. The level of coherent stresses is higher in case of the $\gamma^{\prime \prime}$ phase because of larger tetragonal distortions, which are suggested to be a reason for the greater level of embrittlement. Above approximately $700^{\circ} \mathrm{C}$, the $\gamma^{\prime \prime}$ phase becomes unstable and is being transformed into the detrimental $\delta$ phase with the orthorhombic crystal structure [13]. This phase is localized preferentially along the grain boundaries and serves as strong traps for the hydrogen atoms leading to an increased level of embrittlement with a 'pseudo-intergranular' character of the fracture surface [10].

As the hydrogen entry starts from the surface, the probability of hydrogen-atoms' migration to the potential sites of their accumulation 
is important. If so, two factors are expected to control the level of hydrogen supply to the accumulation zones: (i) the activation enthalpy of hydrogen migration that controls the diffusion and (ii) the binding enthalpy of hydrogen atoms to dislocations, which are known to be a carrier for the accelerated hydrogen transport. This mechanism is strongly supported by many experimental studies where an enhanced diffusion and penetration depth were established [15-18]. As shown in [17], the tritium desorption from the sample of nickel-based alloy 600 is by 10 times higher in the course of straining. In case of Inconel 718, it was shown in [18] that a correlation exists between the level of embrittlement and the degree of hydrogen segregation to mobile dislocations.

In addition, the hydrogen effect on dislocation properties itself could lead to the microcrack formation and results in a macrobrittle failure. As shown in the studies of deformation structure of Inconel 718 [9], the hydrogen reduces the spacing between the deformation bands at early stages of deformation and, thus, promotes formation of dislocation pile-ups with the final fracture along the deformation bands.

The aim of the present study was to analyse features of hydrogen atoms mobility and their interactions with dislocations in the asquenched precipitation-free superalloy Inconel 718.

\section{EXPERIMENTAL}

An Inconel 718 nickel-based alloy with the chemical composition shown in Table 1 has been chosen for the studies. To obtain the wire, the samples were cold forged and drawn with the intermediate annealing to the diameter of $1 \mathrm{~mm}$ with the subsequent electrolytic etching. The final heat treatment was performed at $1100^{\circ} \mathrm{C}$ for $40 \mathrm{~min}$ followed by water quenching. Such a treatment allowed to dissolve existing strengthening phases and to obtain the single-phase f.c.c. structure with a small amount of carbides. As shown in [14] using ThermoCalc program, above $1038^{\circ} \mathrm{C}$, the $\gamma$ matrix in the nickel-based alloy having the composition close to the given in Table 1 is expected to be in the equilibrium with $\mathrm{M}_{x} \mathrm{C}$ carbides, where $\mathrm{M}$ stands for $\mathrm{Nb}, \mathrm{Ti}, \mathrm{Mo}$ and/or Cr.

For the mechanical spectroscopy measurements, the samples were electrolytically thinned to different diameters starting from 0.5 to $0.85 \mathrm{~mm}$. For the mechanical tests, the diameter of samples was equal

TABLE 1. Chemical composition of Inconel 718 alloy.

\begin{tabular}{l|c|c|c|c|c|c|c|c|c|c|c}
\hline Elements & $\mathrm{Fe}$ & $\mathrm{Cr}$ & $\mathrm{Nb}$ & $\mathrm{Mo}$ & $\mathrm{Si}$ & $\mathrm{Mn}$ & $\mathrm{Co}$ & $\mathrm{Ti}$ & $\mathrm{W}$ & $\mathrm{Cu}$ & $\mathrm{Ni}$ \\
\hline \% mass & 17.0 & 15.5 & 4.3 & 2.3 & 0.25 & 0.2 & 0.2 & 1.28 & $<0.1$ & $<0.1$ & Balance \\
\hline
\end{tabular}


to $0.75 \mathrm{~mm}$.

Hydrogen charging has been carried out in the aerated $1 \mathrm{~N} \cdot \mathrm{H}_{2} \mathrm{SO}_{4}$ solution containing $100 \mathrm{mg} / 1 \mathrm{NaAsO}_{2}$ to prevent the recombination of hydrogen atoms. The current density and charging time were 50 $\mathrm{mA} / \mathrm{cm}^{2}$ and 72 hours, respectively. To prevent the hydrogen degassing, the samples were stored in liquid nitrogen after the charging.

Measurements of internal friction were carried out using an automated inverted pendulum operating at different frequencies within a certain temperature range. Two kinds of measurements were performed: the temperature-dependent internal friction (TDIF) and amplitude-dependent internal friction (ADIF). In case of TDIF, the oscillation frequency varied from 0.68 to $4.45 \mathrm{~Hz}$, the temperature was changed from $77 \mathrm{~K}$ to $550 \mathrm{~K}$ and the strain amplitude was about $5 \cdot 10^{-6}$. The ADIF measurements were carried out in the temperature range of $77 \mathrm{~K}$ to $195 \mathrm{~K}$ at the frequency of $3.4 \mathrm{~Hz}$. The strain amplitude varied from $4 \cdot 10^{-6}$ to $7 \cdot 10^{-4}$. The heating rate was equal to $1.5 \mathrm{~K} \cdot \mathrm{min}^{-1}$.

The mechanical tests of the hydrogen-charged and hydrogen-free samples were performed at room temperature using a machine $\mathrm{H} 5-\mathrm{K}-\mathrm{T}$ of Hounsfield Company. Two loading rates were applied: $5 \cdot 10^{-4} \mathrm{~s}^{-1}$ and $2.5 \cdot 10^{-4} \mathrm{~s}^{-1}$. The loading and strain data were written in the output file.

\section{RESULTS}

The mechanical spectroscopy measurements were performed to study hydrogen atoms_migration in the bulk solid solution, mobility of dislocations and interaction between hydrogen atoms and dislocations. According to the analysis of hydrogen solubility performed in [19], because of the precipitates, the population of traps in the Inconel 718 is much higher in comparison with pure nickel or austenitic steels. Such a large number of traps could significantly decrease the quantity of the diffusible hydrogen in the alloy. On the other hand, it is known that the intensity of Snoek-like relaxation is proportional to the concentration of diffusible hydrogen, which allows estimating the trapping effect.

\subsection{Temperature-Dependent Internal Friction}

The experimental measurements of the TDIF spectra for the hydrogenfree and hydrogen-charged samples at different frequencies of induced vibrations are presented in Fig. 1. As it is seen, the H-charged spectra of Inconel 718 alloy consist of two broad peaks located in between 125 $\mathrm{K}$ to $275 \mathrm{~K}$ and $275 \mathrm{~K}$ to $475 \mathrm{~K}$, respectively. The spectrum of the $\mathrm{H}$ free sample reveals no evidence of internal friction peaks. The variation in the oscillation frequency results in the shift of the low tempera- 


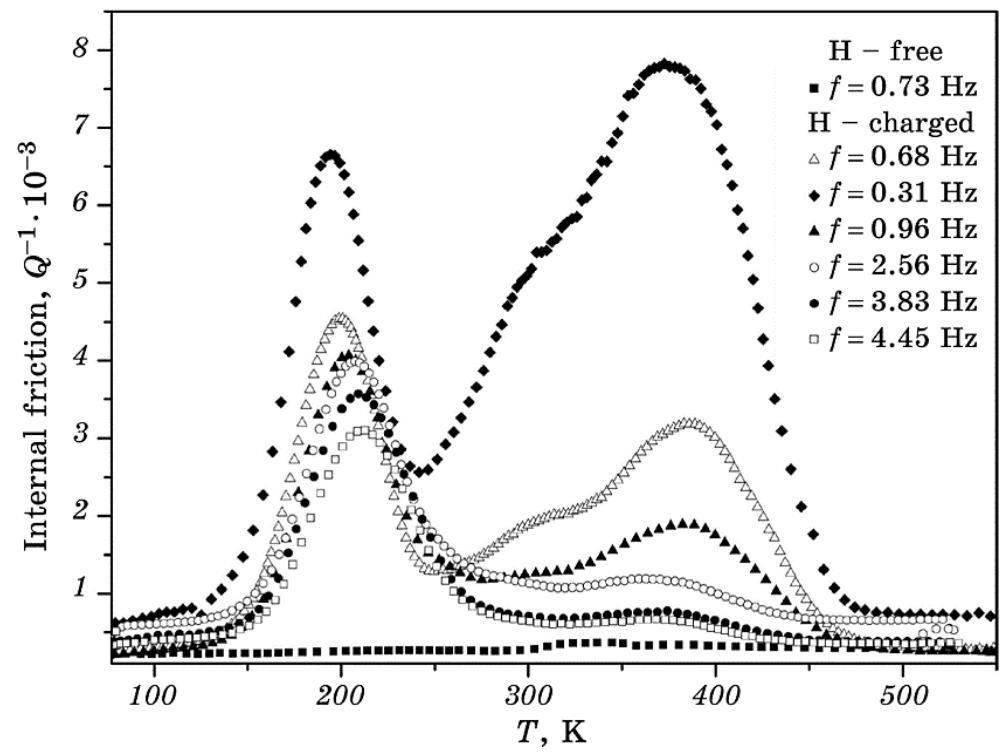

Fig. 1. Temperature-dependent internal friction in the hydrogen-charged and hydrogen-free specimens of Inconel 718 alloy.

ture peak, which indicates on its relaxation nature, whereas the position of high temperature one remains unchanged and it is a feature of a transient processes occurring in the $\mathrm{H}$-charged material. The relaxation peak is of Snoek-like type caused by the stress-induced diffusion jumps of hydrogen atoms in their complexes with the substitutional atoms.

For the more precise analysis of the relaxation peaks, the fitting procedure to the experimentally obtained spectra has been applied. Figure 2 represents an example of fitting as a function of the inverse temperature after the subtraction of the TDIF background. As it is seen, both the low-temperature and high-temperature peaks have a complex nature and consist of two and tree sub-peaks, respectively. The sub-peaks profiles have been fitted using the broadened Debye equation by considering the lognormal distribution of activation parameters, as described in [29].

The transient processes, which are responsible for the highertemperature peak, are usually related to hydrogen degassing and/or its redistribution among the crystal lattice defects. As mentioned above, theoretical predictions using the ThermoCalc program package [14, 15] indicate on the presence of the titanium, niobium and molybdenum carbides after the performed solution treatment. Such carbides can be the traps for the hydrogen atoms, and the redistribution of hydrogen within such traps could be a reason for the appearance of three transient sub-peaks P3, P4 and P5. 


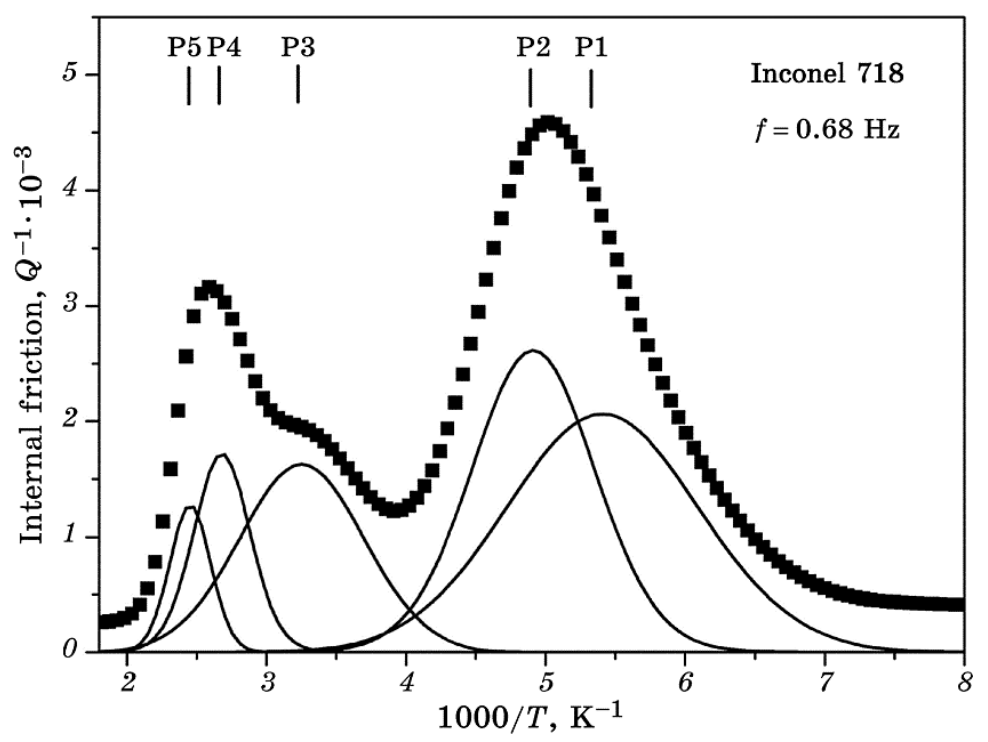

Fig. 2. Example for the fitting of IF peaks after the subtraction of the IF background.

As concerns the low-temperature peak, the fitting reveals the existence of two Snoek-like relaxation sub-peaks, marked as P1 and P2, respectively (see Fig. 2). The relaxation nature of such peaks is related to their thermally activated character, and the treatment of experimental data in the Arrhenius co-ordinates allows to determine the activation enthalpy of hydrogen-atoms' migration.

The obtained results are presented in Fig. 3. As it follows from the analysis, the relaxation peaks have the activation enthalpies of $0.41 \pm$ $\pm 0.02 \mathrm{eV}$ for $\mathrm{P} 1$ and $0.42 \pm 0.05 \mathrm{eV}$ for $\mathrm{P} 2$ with the relaxation times

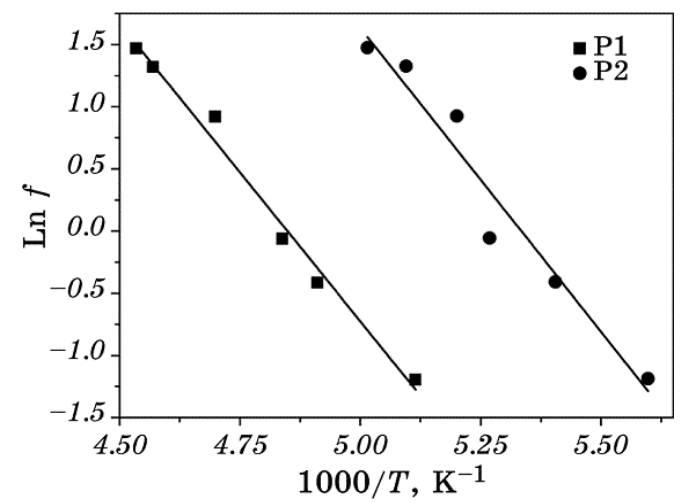

Fig. 3. The frequency shift of temperature of the Snoek-like relaxation peaks in the Arrhenius co-ordinates. 
$\tau\left(\mathrm{P}_{1}\right)=(8.17 \pm 0.49) \cdot 10^{-11} \mathrm{~s}$ and $\tau\left(\mathrm{P}_{2}\right)=(4.78 \pm 0.53) \cdot 10^{-12} \mathrm{~s}$.

\subsection{Amplitude-Dependent Internal Friction}

The performed ADIF measurements allowed studying the interaction between the hydrogen atoms and the dislocations and calculating the corresponding binding enthalpy. The effect of hydrogen on the ADIF of Inconel 718 is shown in Fig. 4. The internal friction background caused by the vibrations of dislocations segments under the applied stress and is proportional to the area crossed by moving dislocations in the course of vibrations [21,22]. As it is seen, hydrogen increases the internal friction background, which suggests the enhancement of dislocations mobility. After hydrogen degassing, the level of IF background decreases almost to the initial value with some insignificant excess, which is caused by the increase in the dislocations density due to severe cathodic hydrogen charging.

Important is the value of critical strain, $\varepsilon_{\mathrm{cr}}$, above which the internal friction acquires the amplitude dependence. According to the theory proposed by Granato and Luecke [23, 24], the internal friction becomes strain-dependent, if the applied stress is sufficient to break dislocations away from their pinning points. However, as shown later in some experiments [25, 26] and confirmed theoretically [27], the stress needed for the breakaway of dislocations from their pinning points in the annealed metals is too high and can even exceed the yield and ultimate strength. This means that the emission of new dislocations by dislocation sources should occur before the unpinning of the pre-existing ones. Therefore, the critical value of strain $\varepsilon_{\mathrm{cr}}$ is related to the start of

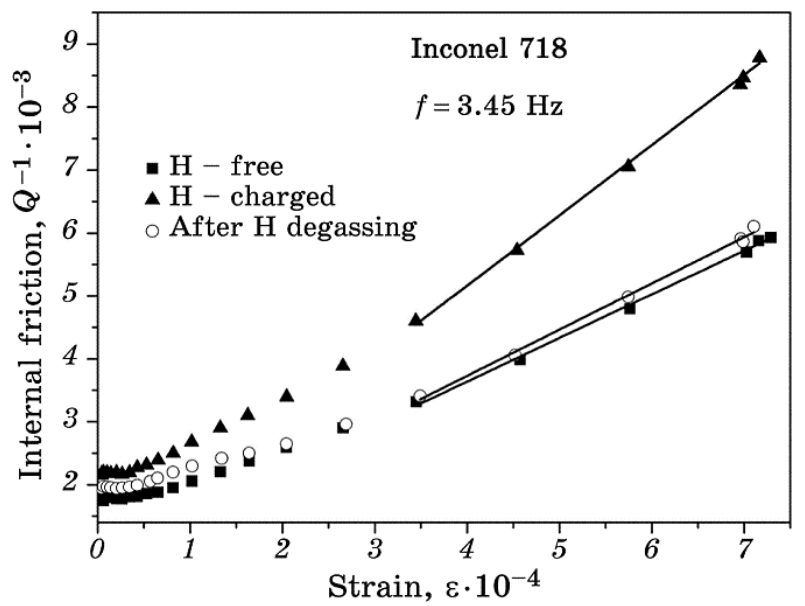

Fig. 4. Amplitude-dependent internal friction in the hydrogen-free sample, after hydrogen charging, and subsequent hydrogen degassing. 
microplastic deformation and the hydrogen decreases its value.

An important parameter in the ADIF measurements is the slope of the amplitude dependent part of internal friction, $d Q^{-1} / d \varepsilon$. In the temperature range, where the hydrogen atoms are not sufficiently mobile to follow the dislocations, the slope is controlled by the intersection of the pinned dislocation forest by the moving dislocations and it does not depend on temperature or slightly depends on it. As it is seen in Fig. 4, hydrogen increases the slope of the amplitude dependent part of the experimental curve in comparison with that for the hydrogen-free sample. With increasing temperature, hydrogen atoms acquire mobility and can follow the dislocations during their vibrations. It this case, the $d Q^{-1} / d \varepsilon$ slope should depend on migration of interstitial atoms and their binding to dislocations. Thus, the slope of the IF amplitudedependent part becomes temperature dependent. Such a behaviour is represented in Fig. 5 and the treatment of experimental data in the coordinates $\ln \left(\Delta Q^{-1} / \Delta \varepsilon\right)$ versus the inverse temperature is shown in the inset. The temperature, above which the angle becomes temperature dependent, is denoted as condensation temperature, $T_{\mathrm{C}}$, for the clouds of interstitial atoms at dislocations. For the studied material, its value is equal to $149 \pm 2 \mathrm{~K}$. The analysis of the temperature dependence for the slope of the amplitude-dependent part of internal friction in the

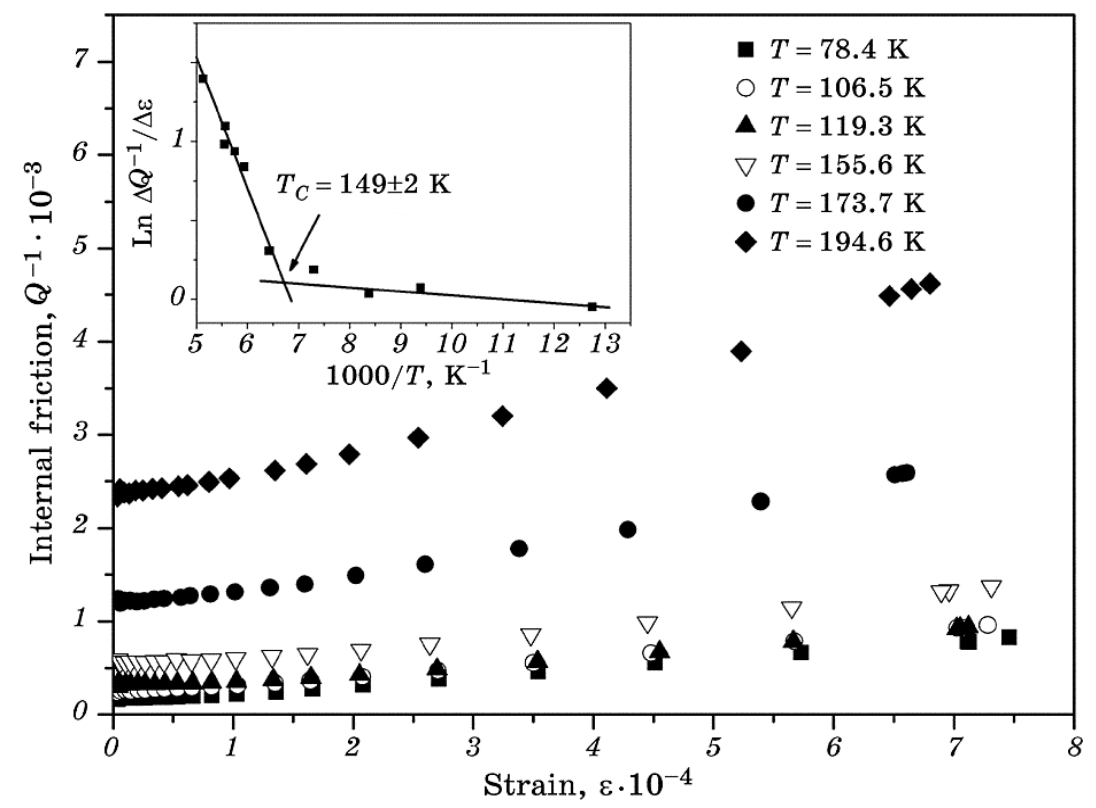

Fig. 5. Amplitude-dependent internal friction at different temperatures. The inset shows how mobility of dislocations depends on the temperature; $T_{\mathrm{C}}$ is the temperature for the condensation of hydrogen clouds around the dislocations, of which above the hydrogen atoms accompany the moving dislocations. 
Arrhenius co-ordinates, see inset to Fig. 5, allows to determine the binding enthalpy of hydrogen atoms to dislocations $H_{b}=0.072 \pm 0.005$ $\mathrm{eV}$.

\subsection{Mechanical Tests}

The degree of hydrogen embrittlement and the effect of hydrogen on the macroscopic characteristics of the Inconel 718 were studied using mechanical tests. The experimental engineering stress-strain curves of the hydrogen-charged and hydrogen-free specimens are presented in Fig. 6, and the corresponding data are given in Table 2. The hydrogen embrittlement index, $\mathrm{HE}$, has been estimated as a corresponding decrease in the relative elongation, $\delta$ :

$$
\mathrm{HE}=\frac{\delta_{0}-\delta_{\mathrm{H}}}{\delta_{0}} \times 100 \%,
$$

where $\delta_{0}$ and $\delta_{\mathrm{H}}$ belong to the $\mathrm{H}$-free and $\mathrm{H}$-charged samples, respectively.

As follows from the obtained data, the hydrogen charging results in decreasing the elongation to failure. At the same time, hydrogen increases the yield stress and decreases the ultimate tensile stress (UTS). The measurements also show that the degree of embrittlement_depends on the applied strain rate. A slower strain rate results in the higher level of embrittlement. The UTS value is also smaller in comparison with that at higher strain rate of $\mathrm{H}$-charged samples, whereas the yield stress is not affected.

\section{DISCUSSION}

The obtained results of the internal friction measurements and mechanical tests are the source of important information about affinity of the alloy Inconel 718 to hydrogen brittleness. The internal friction study of Inconel 600 alloy has been previously reported in [28]. The Snoek-like relaxation peak was analysed based on the idea of different

TABLE 2. Mechanical properties of the H-charged and H-free specimens of Inconel 718 alloy.

\begin{tabular}{ccccccc}
\hline & $d \varepsilon / d t, \mathrm{~s}^{-1}$ & $\sigma_{0.2} \pm 4, \mathrm{MPa}$ & $\sigma_{\mathrm{UTS}} \pm 6, \mathrm{MPa}$ & $\varepsilon \pm 1, \%$ & $\mathrm{HE}, \%$ \\
\hline \multirow{2}{*}{ H-free } & $5 \cdot 10^{-4}$ & 330 & 779 & 67 & - \\
\multirow{2}{*}{ H-charged } & $5 \cdot 10^{-4}$ & 368 & 665 & 55 & 18 \\
& $2.5 \cdot 10^{-4}$ & 369 & 634 & 47 & 30 \\
\hline
\end{tabular}


number of iron atoms in the octahedrons around the hydrogen atoms, which should affect the activation enthalpy of hydrogen migration. It was concluded that the relaxation peak could be fitted with one, two or three sub-peaks depending on the charging current during the hydrogenation process.

It has to be taken into account that main substitution elements in the nickel-based Inconel 600 alloy are chromium and iron. Because of the repulsive hydrogen-chromium interaction that follows from the absence of the Snoek-like relaxation in the hydrogen-charged $\mathrm{Ni}-\mathrm{Cr}$ alloys [28], the only element, which can cause distortions from the cubic symmetry around hydrogen atom in the nickel lattice, is the iron. Thus, in general, the varied number of relaxation sub-peaks resulted from the fitting procedure under different charging conditions could be related to the composition-dependent distribution of the octahedrons containing hydrogen and substitution atoms. It is worth noting that a caution should be taken at such analysis because the statistical relaxation model $[30,31]$ could be well applied to the binary systems only (see e.g. [30-33]). The Inconel 600 alloy could be considered as a binary one because, as was mentioned, the chromium atoms are not participating in the relaxation processes, whereas the content of other elements is rather small to cause a definite statistical effect. Therefore, the relaxation peaks could be attributed to the jumps of hydrogen atoms having a different number of iron atoms in the nearest neighbourhood.

The above-mentioned approach cannot be applied to the studied case of hydrogen-charged Inconel 718 alloy. Because of the higher content of alloying elements in comparison with Inconel 600 and owing to the possible hydrogen interactions with such elements, their role in the relaxation processes should be different. Moreover, the deconvolution procedure of the observed broad relaxation peak reveals that it can be well described by two sub-peaks with the same values of activation enthalpy but different relaxation times. This particular behaviour denoted as 'frozen splitting' is caused by the defects having orthorhombic symmetry. It appears in the solid solutions with a rather high total content of substitution solutes resulting in the reorientation of complexes of an interstitial atom with two substitutional atoms. This orthorhombic defects in f.c.c. crystal lattice causes two shear relaxations in directions $<\mathbf{1 0 0}>$ and $<111>$ with different modulus defects and, correspondingly, different relaxation times [29,34].

The estimated value of the activation enthalpy for the hydrogenatom migration can be compared with available data in literature. The range of hydrogen migration enthalpies, as determined in [35-37] for the Inconel 718 , is about $0.47-0.52 \mathrm{eV}$. These values are higher in

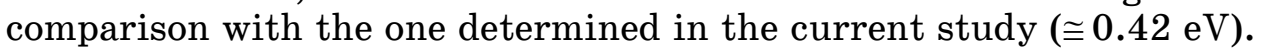
The discrepancy could be attributed to the experimental technique 
used for the measurements. In fact, all the previous experimental values were obtained using the hydrogen permeation technique. A feature of such measurements is that the analysis of the transient curve gives the value of the so-called 'effective diffusivity', which includes the effect of all possible defects on the diffusion coefficient during the hydrogen-atoms' permeation. Such defects, which can be the trapping sites for the hydrogen atoms and increase in the value of the activation energy, are the grain boundaries, precipitates, intersections of slip bands and vacancies. In contrast, the Snoek-like relaxation considers only the diffusion jumps of hydrogen atoms in the crystal lattice. Therefore, the determined parameter of the hydrogen migration energy can be considered as that for the precipitation-free matrix and used, for instance, as input parameter in empirical simulations.

As it was mentioned in the introduction, dislocations play an important role in hydrogen atoms transport to the places of their potential accumulations. As follows from the ADIF measurements (see Figs. $4,5)$, hydrogen decreases the value of critical strain for the microplastic deformation, which results in the early start of dislocation sources activation.

At the same time, the slope of the IF amplitude-dependent part is increased. The value $d Q^{-1} / d \varepsilon$ is proportional to the area swept by dislocations during their vibrations, which corresponds to the increase in dislocation mobility. Such processes are significant for the Inconel 718 alloy because, in general, the fracture occurs via the slip channelling mechanism [38]. The precipitations are the main strengthening components in Inconel 718 and, if the dislocations cut through the particles, it creates a condition for the localization of deformation. Hydrogen can facilitate this process because it decreases the stacking fault energy [39, 40]. Therefore, it decreases the cross-slip probability and, being accumulated in the dislocation pileups in front of the particle, it decreases the distance between dislocations, increasing thereby the stress at the leading dislocation in the pileup and assisting the cutting through the particles $[41,42]$. Under such condition, along with the hydrogen mobility, important characteristics are the binding enthalpy of hydrogen atoms to dislocations and the condensation temperature of hydrogen clouds around them. As shown in [43], the condensation temperature, $T_{\mathrm{C}}$, characterizes the temperature for the initiation of hydrogen embrittlement, and the correlation exists between $H_{m}, H_{b}$ and $T_{\mathrm{C}}$. Above this temperature, the hydrogen clouds start to be diluted, and mobility of hydrogen atoms and their binding to dislocations determine the extension of hydrogen-brittleness temperature range. With higher values of $H_{m}$ and $H_{b}$, the hydrogen embrittlement temperature range should be shifted to higher temperatures.

The mechanical test experiments, as shown in Fig. 6, confirm the embrittlement of the Inconel 718 alloy. Mechanical properties of the 


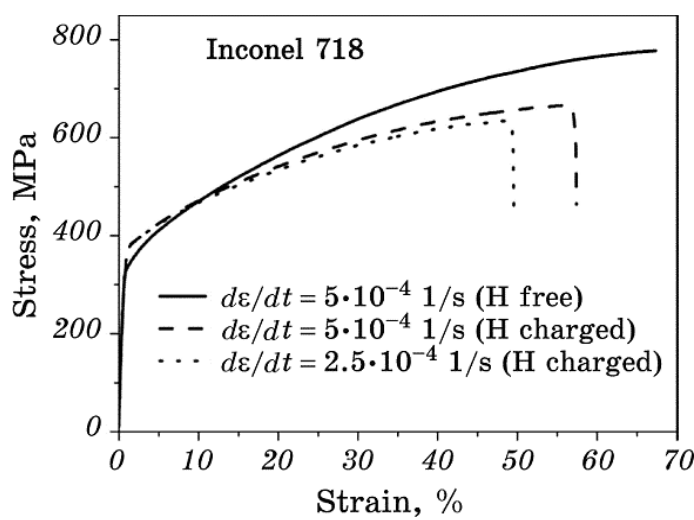

Fig. 6. Engineering stress-strain curves of the hydrogen-charged and hydrogen-free specimens at different strain rates.

$\mathrm{H}$-free samples correspond to the used heat treatment: the absence of precipitates results in lower values of the yield and ultimate stresses but higher plasticity (see Table 2). Hydrogen affects all these properties in a different manner. As it was mentioned by several authors, the hydrogen does not affect the yield stress [19, 44, 45], particularly, for the nickel-based materials. In contrast, the present study reveals that the hydrogen increases this value. A reason for such contradiction could be explained based on the difference in the hydrogen charging procedure. The cathodic charging results in a huge hydrogen concentration profile under the specimens surface. As shown in [46], it corresponds to the high strain level and corresponding hardening because of the intensive dislocations generation. Nevertheless, owing to a smaller hydrogen migration enthalpy in comparison, e.g., with that in austenitic steels, the more or less homogeneous distribution could be achieved even under the cathodic charging with low current density.

While the mechanical test shows an increase of the yield strength, the internal friction measurements indicate on the hydrogen-caused decreased stress for the activation of dislocation sources along with increased dislocation mobility. These results represent that, on the microscopic scale, the hydrogen has the localized softening effect, which could not be revealed by macroscopic properties.

\section{CONCLUSIONS}

Based on internal friction measurements and mechanical tests, the role of hydrogen-dislocation interactions in the embrittlement of Inconel 718 alloy has been studied, and the following conclusions can be derived.

1. Hydrogen decreases the stress for the activation of dislocation 
sources and increases velocity of dislocations in the alloy Inconel 718 .

2 . The enthalpies of hydrogen migration, binding of hydrogen atoms to dislocations, and the condensation temperature for the hydrogen clouds at dislocations are important parameters, which determine the temperature range of hydrogen embrittlement.

3. Hydrogen effects on the microscopic and macroscopic scales are completely different. In consistency with the HELP theory, despite on the macroscopic brittleness, the hydrogen-caused localized softening occurs.

\section{ACKNOWLEDGMENT}

The author would like to thank Prof. Valentin Gavriljuk for the helpful discussion and valuable comments during the article preparation.

\section{REFERENCES}

1. E. E. Brown and D. R. Muzyka, Nickel-Iron Alloys (Eds. C. T. Sims and N. S. Stoloff) (New York: Wiley: 1987), p. 165.

2. K. M. Chang and A. H. Nahm, Rene 220: 100 F Improvement Over Alloy 718 (Eds. E. A. Loria). Superalloy 718 - Metallurgy and Applications (Warrendale, PA: Minerals, Metals \& Materials Society: 1989), p. 631.

3. I. Kirman and D. H. Warrington, J. Inst. Met., 99: 197 (1971).

4. Y. F. Han, P. Deb, and M. C. Chaturvedi, Met. Sci., 16: 825 (1982).

5. R. Cozar and A. Pineau, Metall. Trans., 4: 47 (1973).

6. J. M. Oblak, D. F. Paulonis, and D. S. Duvall, Metall. Mater. Trans., 62: 611 (1969).

7. J. W. Brooks and P. J. Bridges, Metallurgical Stability of Inconel Alloy 718. Superalloys (Eds. T. M. Pollock, R. D. Kissinger, R. R. Bowman, K. A. Green, M. McLean, S. L. Olson, and J. J. Schirra) (Warrendale, PA: Minerals, Metals \& Materials Society: 1988), p. 33.

8. I. S. Hwang, R. G. Ballinger, K. Hosoya, and J. W. Prybylowski, J. Electrochem.Soc., 136, No. 6: 1874 (1989).

9. J. He, S. Fukuyama, K. Yokogawa, and A. Kimura, Mater. Trans. JIM, 35: 689 (1994).

10. R. J. Walter and W. T. Chandler, Proc. of an International Conference on the Effects of Hydrogen on Materials Properties and Selection and Structural Design (Champion, USA, 1973) (Eds. I. M. Bernstein and A. W. Thompson), p. 515.

11. P. D. Hicks and C. J. Altstetter, Metall. Trans. A, 21: 365 (1990).

12. P. D. Hicks and C. J. Altstetter, Metall. Trans. A, 23: 237 (1992).

13. S. Azadian, L. Y. Wei, and R. Warren, Materials Characterization, 53: 7 (2004).

14. M. K. Miller, S. S. Babu, and M. G. Burke, Mater. Sci.Eng. A, 270: 14 (1999).

15. J. A. Donovan, Met. Trans. A, 7: 145 (1976).

16. J. K. Tien, A. W. Thompson, I. M. Bernstein, and R. J. Richards, Met. Trans. A, 7: 821 (1976). 
17. F. Lecoester, J. Chene, and D. Noel, Mater. Sci. Eng. A, 262: 173 (1999).

18. L. Fournier, D. Delafosse, and T. Magnin, Mater. Sci. Eng. A, 269: 111 (1999).

19. C. L. Baker, J. Chene, I. M. Bernstein, and J. C. Williams, Metall. Trans. A, 19: 73 (1988).

20. Computed with the Use of the Ni-Data Database, a Thermodynamic Database for Calculation of Phase Equilibria in Multicomponent Alloys (UK: ThermoTech Ltd.).

21. G. Schoeck, E. Bisogni, and J. Shyne, Acta. Metall., 12, No. 6: 1466 (1964).

22. A. Riviere, V. Amirault, and J. Woirgard, Nuovo Cimento, 33: 398 (1976).

23. V. Granato and K. Luecke, J.Appl. Phys., 27, No. 6: 583 (1956).

24. V. Granato and K. Luecke, J.Appl. Phys., 52, No. 12: 7136 (1981).

25. A. S. Keh, Relation Between Structural and Mechanical Properties of Metals (London: H. M. Stationery Office: 1963), p. 436.

26. J. D. Baird, Iron Steel, 36: 450 (1963).

27. J. P. Hirth and J. Lothe, Theory of Dislocations (New York: McGraw-Hill Co.: 1968).

28. P. Aaltonen, Yu. Jagodzinski, A. Tarasenko, S. Smouk, and H. Hanninen, Philos. Mag., 78, No. 4: 979 (1998).

29. A. S. Nowick and B. S. Berry, Anelastic Relaxation in Crystalline Solids (New York: Academic Press: 1972).

30. E. Adler, Metallk., 56: 249 (1965).

31. E. Adler and C. Radeloff, Z. Angew. Phys., 18: 482 (1965).

32. B. Hohler and H. Kronmuller, Philos. Mag., 45, No. 6: 607 (1982).

33. S. M. Myers, M. I. Baskes, H. K. Birnbaum, J. W. Corbett, G. G. DeLeo, S. K. Estreicher, E. E. Haller, P. Jena, N. M. Johnson, R. Kirchheim, S. J. Pearton, and M. J. Stavola, Rev. Mod. Phys., 64: 559 (1992).

34. V. G. Gavriljuk, H. Hanninen, A. V. Tarasenko, A. S. Tereshchenko, and K. Ullakko, Acta Metall. Mater., 43, No. 6: 559 (1995).

35. W.M. Robertson, Metall. Trans., 8: 1709 (1977).

36. J. Xu, X. K. Sun, Q. Q. Liu, and W. X. Chen, Metall. Mater. Trans. A, 25: 539 (1994).

37. ASTM G148-97. Standard Practice for Evaluation of Hydrogen Uptake, Permeation, Transport in Metals by an Electrochemical Technique (2011).

38. D. W. Worthem, I. M. Robertson, F. A. Leckie, D. F. Socie, and C. J. Altstetter, Metall. Trans. A, 21: 3215 (1990).

39. A. E. Pontini and J. D. Hermida, Scr. Mater., 17: 1831 (1997).

40. J. D. Hermida and A. Roviglione, Scr. Mater., 39: 1145 (1998).

41. P. Sofronis and R. M. McMeeking, J.Mech. Phys. Solids, 37, No. 3: 317 (1989).

42. S. M. Teus, V. N. Shivanyuk, B. D. Shanina, and V. G. Gavriljuk, phys. status solidi (a), 204, No. 12: 4249 (2007).

43. S. M. Teus, D. G. Savvakin, O. M. Ivasishin, and V. G. Gavriljuk, Int. J. Hydr. Energy, 42: 2424 (2017).

44. A. W. Thompson and I. M. Bernstein, Advances in Corrosion Science and Technology (Eds. M. G. Fontana and R. F. Staehle) (New York: Plenum Press: 1980), p. 53.

45. J. P. Hirth, Metall. Trans. A, 11: 861 (1980).

46. G. S. Mogilny, S. M. Teus, V. N. Shyvanyuk, and V. G. Gavriljuk, Mater. Sci. Eng. A, 648: 260 (2015). 